\title{
ENTREVISTA
}

\section{La publicación de la Ley de 1 de Marzo de 1940 sobre represión de la masonería y del comunismo y el discurso antimasónico en la prensa asturiana. El caso del diario Voluntad de Gijón (1940-1963)}

El investigador Javier F. Granda ha defendido un Trabajo Final de Máster (TFM) cuyo título es "La publicación de la Ley de 1 de Marzo de 1940 sobre represión de la masonería y del comunismo y el discurso antimasónico en la prensa asturiana. El caso del diario Voluntad de Gijón (1940-1963)" en la Universidad Nacional de Educación a Distancia (UNED) en España, en septiembre de 2015. Javier F. Granda nació en 1971 en España.

El autor nos ha concedido la siguiente entrevista.

¿Cuáles fueron los motivos que le llevó a enfocar su investigación hacia la Masonería?

Tras haberme licenciado en Historia por la UNED, haber realizado un máster en Historia y Análisis Sociocultural en la Universidad de Oviedo y un Experto universitario en Criminología por la UNED, decidí continuar mis estudios de postgrado en el programa modular "Órdenes, Corporaciones, Academias y Sociedades: Historia de los Movimientos Asociativos" de la UNED, donde realizo el máster en Historia de la Masonería en España. Dentro de este programa modular curso las tres especialidades: el referido máster, el Especialista en "Historia de las Órdenes, Corporaciones, Academias y Sociedades Filantrópicas y Fraternales" y el Experto universitario en "Historia de la Masonería en España y América”. Me guía un claro interés por la investigación en diferentes aspectos de la Historia Contemporánea y el programa modular me resultó muy atractivo dado el nivel y la altura intelectual de los especialistas que estaban al cargo del mismo. Investigadores como Javier Alvarado, José Antonio Ferrer Benimeli y el propio director de mi TFM, Juan José Morales, me inspiraron una confianza absoluta a la hora de decidir profundizar en este ámbito de la Historia.

Como a todo profano, la masonería me resultaba una cuestión hermética y oscura, sobre lo cuál reconozco en ello la huella de ciertos prejuicios de una sociedad que sufrió una dura represión durante cuarenta años bajo la educación en unos valores distorsionados que propagaron una imagen muy alterada de múltiples aspectos de la realidad social. Sin ser un testigo de la represión, ya que he crecido en la época de transición democrática en España, vislumbro una nebulosa de referencias en el que la masonería era una cuestión poco menos que innombrable. En cierta medida, querer penetrar en ese misterio, que no es otra cosa que 
la ceguera de una sociedad fuertemente manipulada, es lo que me ha llevado a interesarme por este tema. Obviamente me adentro en este terreno con las armas del historiador y con una mente limpia.

¿Cuáles fueron las fuentes que ha utilizado?

En mi trabajo he utilizado la prensa como fuente fundamental. Extraigo el volumen de la información de la prensa asturiana y lo someto a una crítica que viene dada por las fuentes bibliográficas que empleo como elemento organizativo. Me sirvo de diversa bibliografía sobre la Historia Contemporánea de España que permite comprender de inmediato cuál es la problemática del objeto de estudio y cuáles son los ejes principales que lo definen. Me detengo en una serie de normas legales que van a regir durante años y observo la realidad que estas provocan. Centro mi análisis en la prensa asturiana y observo las particularidades de la misma así como los aspectos comunes al resto de la prensa española. Como afirmo en mi texto, la prensa es una fuente de primer orden para conocer la diversidad, tanto de la información y las cuestiones relacionadas con el día a día de las sociedades, como de los individuos, mentalidades, etc., y por ello debe estudiarse desde diferentes perspectivas que abarquen múltiples realidades, pero conscientes también de su manipulación y de toda la información que pueda quedar fuera de su alcance.

¿Cuáles fueron las principales dificultades con las que se ha encontrado? ¿Cómo las ha superado?

La mayor dificultad que se produce en cualquier trabajo es el factor tiempo. En este caso asociado al volumen de información manejada, ya que, para reflejar ciertas cuestiones, se han empleado muchas horas de lectura y búsqueda de información de forma manual y analógica en hemerotecas. Se ha avanzado más rápido cuando se han empleado medios digitales de recuperación de información, no obstante los sistemas de reconocimiento que se han aplicado en la digitalización de fuentes no son tan eficaces como para permitir volcar y usar los textos sin una profunda corrección, por lo que he dedicado muchas horas a la transcripción, corrección de textos y confrontación de fuentes a través de diarios nacionales disponibles en versión digital, para recomponer lagunas que, debido a los defectos de impresión en los diarios originales, hacían ilegible la lectura de determinados textos. La información que se presenta en el trabajo lleva implícita una enorme labor de desbroce entre miles de páginas de diarios, limpiando mucho para llegar a lo fundamental y significativo para el objeto de estudio. 
¿Cuáles fueron las principales problemáticas históricas que su trabajo ha resuelto?

En el trabajo se aborda una diversidad de cuestiones referidas a la prensa asturiana y en particular al diario Voluntad de Gijón, observando el modo formal de plantear las noticias que se refieren a la publicación de la Ley de 1 de Marzo de 1940 sobre represión de la masonería y del comunismo en las diferentes cabeceras y también aquellas noticias relacionadas con la represión de las realidades que se regulan en la Ley. Me he ceñido exclusivamente a la información derivada de la prensa escrita. Es un trabajo que no se había abordado en Asturias de esta forma y ayuda a comprender cómo era la prensa asturiana del momento y cómo era su opinión acerca de la masonería y su relación con el Gobierno de España que por medio de la Ley de Prensa de 1938 establecía un control férreo sobre unos medios de comunicación que sirven para propagar la información y el mensaje que va a llegar a los ciudadanos. Este mensaje podía influirles tanto como informarles ya que se establecieron los mecanismos necesarios para que la información que conformase las ideas del ciudadano y la conciencia colectiva, llegase depurada y sometida a un escrupuloso tratamiento. Se buscaba limitar y condicionar la mentalidad del individuo y de la colectividad con información intervenida y manipulada.

¿Por favor, podría resumir la esencia de su Tesis en dos líneas?

En mi opinión, la prensa del franquismo al tratar la masonería, emplea un discurso persistente basado en el fomento de una neurosis colectiva que permita la alienación de los españoles.

¿Cuáles fueron las lecciones, a todos los niveles, personal y profesional, que usted ha deducido de su experiencia investigativa?

Después del propio enriquecimiento por una inmersión tan profunda en la Historia Contemporánea de España, debatiéndome en las entrañas de una cuestión tan compleja como ha sido la represión tras la guerra civil, destaco la valiosa e insustituible colaboración del director de mi trabajo, Juan José Morales, que me ha iluminado en tantos momentos y finalmente ayudado a dar visibilidad al esfuerzo. Una vez concluido todo el trabajo he asistido, invitado por él, al XIV Symposium Internacional de Historia de la Masonería Española celebrado en Gijón entre los días 10 y 12 de septiembre de 2015, en el cuál descubrí los mejores talentos que hoy estudian la masonería dentro y fuera de España. Ha sido un descubrimiento hallar referencias tan importantes y observar la riqueza en las diversas líneas de investigación que se siguen por especialistas de todo el mundo. He recibido la invitación para presentar una ponencia/comunicación en el próximo encuentro 
que se celebrará en Lisboa, lo cuál me sitúa en una dirección clara actualmente.

¿Ahora, cuáles son sus proyectos profesionales?

Continuaré con la investigación en este campo para poder presentar mis resultados en el próximo Symposium Internacional de Historia de la Masonería Española que se celebrará en Lisboa y, en la medida de mis posibilidades, concluir mi carrera universitaria con el doctorado y consolidarme como investigador.

¿Quisiera destacar algún aspecto que no se ha contemplado y que usted consideraría digno de reseñar?

Simplemente deseo agradecer al equipo de REHMLAC+ el interés por mi investigación y por darme la oportunidad de participar en una revista de esta proyección. Deseo también agradecer al equipo del programa "Órdenes, Corporaciones, Academias y Sociedades: Historia de los Movimientos Asociativos", de la Facultad de Derecho, Historia del Derecho y de las Instituciones, de la UNED, y a todos sus colaboradores, por el seguimiento de mi trabajo y la participación en las redes académicas en las que están presentes fomentando la visibilidad de investigaciones como la que he realizado.

Esta entrevista se efectúo de forma telemática el 9 de octubre de 2015.

Autores de la entrevista: Ricardo Martínez Esquivel e Yván Pozuelo Andrés, Director y Editor de REHMLAC+.

DOI: http://dx.doi.org/10.15517/rehmlac.v7i2.22767 